4

\title{
Spatial and temporal heterogeneity of infectious hematopoietic necrosis virus in
} Pacific Northwest salmonids

\author{
Rachel Breyta, Allison Black, John Kaufman, Gael Kurath
}

\begin{abstract}
The aquatic rhaboviral pathogen infectious hematopoietic necrosis virus (IHNV) causes acute disease in juvenile fish of a number of populations of Pacific salmonid species. Heavily managed in both marine and freshwater environments, these fish species are cultured during the juvenile stage in freshwater conservation hatcheries, where IHNV is one of the top three infectious diseases that cause serious morbidity and mortality. Therefore, a comprehensive study of viral genetic surveillance data representing 2,590
\end{abstract} field isolates collected between 1958-2014 was conducted to determine the spatial and temporal patterns of IHNV in the Pacific Northwest of the contiguous United States. Prevalence of infection varied over time, fluctuating over a rough 5-7 year cycle. The genetic analysis revealed numerous subgroups of IHNV, each of which exhibited spatial heterogeneity. Within all subgroups, dominant genetic types were apparent, though the temporal patterns of emergence of these types varied among subgroups. Finally, the affinity or fidelity of subgroups to specific host species also varied, where UC subgroup viruses exhibited a more generalist profile and all other subgroups exhibited a specialist profile. These complex patterns are likely synergistically driven by numerous ecological, pathobiological, and anthropogenic factors. Since only a few anthropogenic factors are candidates for managed intervention aimed at improving the health of threatened or endangered salmonid fish populations, determining the relative impact of these factors is a high priority for future studies.

\section{Introduction}

Pacific salmonid fish are an important cultural and ecological resource in the Pacific Northwest of North America. Due to overfishing and habitat loss, all but one of the six species of Pacific salmonids are cultured to some extent in conservation hatcheries. Among hatchery populations, the rhabdoviral pathogen infectious hematopoietic necrosis virus (IHNV) is a particular burden (Wolf 1988; Bootland \& Leong 1999). IHNV 
32 primarily infects sockeye and kokanee salmon (migratory and freshwater life history

33 types of Oncorhynchus nerka, respectively), Chinook salmon (O. tshawytscha), and

34 steelhead and rainbow trout (migratory and freshwater life history types of $O$. mykiss,

35 respectively). In these hosts IHNV typically causes acute disease and mortality only in

36 juvenile fish, while infection in adults is usually asymptomatic. Both juvenile and adult

37 fish can transmit IHNV horizontally through water. Within hatcheries, transmission from

38 infected adults to progeny via egg-associated virus is greatly reduced or eliminated by

39 egg disinfection (Amend 1975; Meyers 1998). As observed in captive fish, acute IHN

40 disease in juveniles is often associated with epidemic mortality, which can be up to $90 \%$

41 (Groberg 1983a; Groberg 1983b; LaPatra et al. 1993a; LaPatra et al. 1993b; Bootland \&

42 Leong 1999).

43 Established methods for IHNV molecular epidemiology are based on the sequence of

44 a variable portion of the viral glycoprotein gene, the $303 \mathrm{nt}$ midG region. Analysing virus

45 isolate midG sequence genotype data together with epidemiological case data allows

46 inference of probable transmission sources, and some estimates of secondary

47 transmission risk. This method has been used to define recent emergence events and

48 support effective control measures to mitigate losses due to IHN disease (Breyta et al.

49 2013; Breyta et al. 2016b). A previous molecular epidemiology study of $393 \mathrm{IHNV}$

50 isolates collected throughout the entire range of IHNV in North America revealed three

51 phylogenetic genogroups designated U, M, and L (Kurath 2003). U genogroup viruses

52 are found in Alaska, Western Canada, Puget Sound, Coastal Washington, and the large

53 Columbia River basin that extends throughout much of Washington, Oregon, Idaho, and

54 Montana. M genogroup viruses are also found in the Columbia River basin, as well as

55 sporadic emergence events in coastal Washington (Breyta et al. 2013) and Oregon (this

56 paper). L genogroup viruses have only ever been detected in California and the southern

57 Oregon coastal region. Subsequent phylogenetic analyses have identified six subgroups

58 within the M genogroup, designated MA-MF (Troyer et al., 2003), two subgroups within

59 the U genogroup, designated UC and UP (Black thesis 2015), and two subgroups within

60 the L genogroup, designated L1 and L2 (Kelley et al. 2007).

$61 \mathrm{U}$ and M group IHNV have coexisted within the large complex Columbia River basin

62 for decades (Garver et al. 2003). During that time, M group viruses caused serious 
63 disease impacts to conservation hatchery populations of steelhead trout and farm

64 populations of rainbow trout (Garver et al. 2003; Troyer \& Kurath 2003; Breyta et al.

65 2016b). These M group viruses are not uniformly distributed throughout the Columbia

66 basin, despite the fact that the $O$. mykiss host species can be found in all parts of the

67 watershed. Within one portion of the basin, dominant $\mathrm{M}$ virus types have been observed

68 to exhibit serial emergence and displacement patterns, prompting investigations into

69 possible mechanisms (Kell et al. 2014; Breyta et al. 2016a). Viruses in the U genogroup

70 are also not uniformly distributed, and a recent study revealed population genetic

71 structure (subgroups UP and UC) within the U group IHNV viruses in the Columbia

72 River basin (Black 2015). In this region the UC subgroup is mostly associated with

73 Chinook salmon and steelhead trout, and the UP subgroup is associated with sockeye

74 salmon (Black thesis 2015). While mortality in Chinook salmon due to UC viruses has

75 not been reported at levels similar to that of steelhead trout infected with M group IHNV,

76 disease outbreaks have occurred in juvenile Chinook salmon, and the impact of UC

77 viruses in Chinook salmon conservation programs is not well characterized.

78 In order to determine the spatial and temporal distribution of IHNV subgroups and

79 dominant genetic types in this region, an updated comprehensive molecular epidemiology

80 analysis focusing on IHNV in the Columbia basin, coastal Oregon, coastal Washington,

81 and Puget Sound was conducted. Compared to earlier studies, some IHNV subgroups

82 were still detected, while others were no longer evident (MA, ME, MF) (Troyer \& Kurath

83 2003). The analysis revealed that all subgroups exhibited heterogeneity in temporal and

84 spatial occurrence, despite the availability of host species throughout the study area.

85 Variation in host-specific patterns was observed for different virus subgroups, and both

86 specialist and generalist viral strategies were observed. Several dominant virus genotypes

87 were identified within the $\mathrm{U}$ and $\mathrm{M}$ genogroups, and specific focus sites with high levels

88 of disease impacts were observed. Within this complexity there are novel insights with

89 potential for contributions to targeted control strategies in the future.

\section{Methods}

$92 \quad$ 2.1 Virus Isolates. The molecular biology program at the USGS Western Fisheries

93 Research Center (WFRC) provides midG sequence analysis of IHNV field isolates as a 
94 technical assistance service to fisheries managers throughout the Pacific Northwest. The

95 data generated is maintained in a database at WFRC. This database has a freely

96 accessible internet version at http://gis.nacse.org/ihnv/.

97 IHNV isolates and diagnostic records were obtained from fish health laboratory staff

98 from the United States Fish and Wildlife Service, Washington Department of Fish and

99 Wildlife, Northwest Indian Fisheries Commission, Oregon Department of Fish and

100 Wildlife, Idaho Department of Fish and Game, and from the archival collection at the

101 WFRC. Samples were taken from dead, dying, or asymptomatic juvenile fish or from

102 asymptomatic adult fish and processed for virus isolation in cell culture using

103 standardized protocols (American Fisheries Society Fish Health Section Blue book).

104 Virus culture supernatants of low passage number $(\leq 2$ passages for the majority of

105 isolates) were sent to WFRC for analysis and archival storage at $-80^{\circ} \mathrm{C}$. The $2590 \mathrm{IHNV}$

106 isolates in this study were collected from a total of 252 different sites within the study

107 region and represented 1469 distinct IHNV positive fish cohorts. These samples came

108 from steelhead or rainbow trout (O. mykiss), Chinook salmon (O. tshawytscha), sockeye

109 or kokanee salmon (O. nerka), coho salmon (O. kisutch), chum salmon (O. keta), Atlantic

110 salmon (Salmo salar), or unknown hosts.

$111 \quad 2.2$ Bias and coding by detection events Fish cohorts at hatcheries are tested by

112 agency staff for IHNV infection primarily under three different testing schemes: routine

113 screening of asymptomatic adult fish when they are spawned, occasional screening of

114 asymptomatic juvenile fish, and diagnostic testing of juvenile fish suffering mortality or

115 exhibiting signs of IHNV infection. When positive samples from these testing strategies

116 are submitted for viral genetic typing, two kinds of sampling bias may occur. One is

117 when few samples are submitted for sequence analysis from specific geographic areas

118 because the presence of IHNV in those fish cohorts is not unusual, and a greater number

119 are submitted from fish cohorts that are unexpectedly positive. This pattern creates a

120 geographic surveillance-pressure bias: fish cohorts from areas with newly emergent

121 IHNV are typed more heavily while fish in IHNV endemic areas are sampled and typed

122 less intensely. The second form of bias is in the number of IHNV isolates submitted for

123 typing. For example, one incident of juvenile epidemic IHN disease may be represented

124 by only one or two isolates, while another may be represented by as many as thirty. If 
125 IHNV detections were reported by the raw number of typed isolates, these two sampling

126 biases would mask important patterns. To correct this second form of bias, isolates have

127 been coded into positive fish cohorts (by collection site, age, species, and seasonal

128 timing,(Breyta et al. 2013)). After genetic typing, fish cohorts for which all virus isolates

129 had identical sequence types were each assigned to one 'detection event'. If more than

130 one sequence type was detected among multiple isolates from one cohort, a separate

131 event was assigned for each sequence type detected (Breyta et al., 2013; Breyta et al,

132 2016). In the current report, cohorts with more than one virus type are described as

133 having a 'dominant variant' and 'non-dominant variant(s)'.

$134 \quad 2.3$ Viral RNA extraction and sequence analysis Viral genomic RNA was extracted

135 from $200-500 \mu \mathrm{L}$ of virus culture supernatant with TriReagent (Sigma) according to

136 manufacturer's directions with tRNA (Promega) added to aid in RNA precipitation.

137 Reverse transcription and amplification of a $\sim 550 \mathrm{bp}$ fragment containing the midG

138 region was performed as previously described (Emmenegger et al. 2000) in one $50 \mu \mathrm{L}$

139 reaction using avian myeloblastosis virus (AMV) reverse transcriptase, Taq polymerase,

140 IHNV-specific primers and 30 cycles of amplification. The PCR product was purified

141 away from amplification components using Strataprep PCR purification columns

142 (Agilent Technologies), and $0.5 \mu \mathrm{L}$ was used in each of two $10 \mu \mathrm{L}$ Big Dye Terminator

143 (Applied Biosystems) sequencing PCR reactions, using the same forward and reverse

144 primers as above and 30 cycles as previously described (Emmenegger et al. 2003).

$145 \quad 2.4$ Phylogenetic analysis Sequence data was assembled, edited, and trimmed to the

146 established midG 303nt fragment (Emmenegger et al. 2003; Garver et al. 2003; Kurath et

147 al. 2003; Troyer \& Kurath 2003) using Sequencher software v4.9. Consensus midG

148 sequences for each virus isolate were aligned in Clustalx (Qt/QMake), and manually

149 inspected and corrected for artefactual gap insertion. The term 'genotyping' is used to

150 describe this process, and the term 'sequence type' or 'genetic variant' is used to describe

151 individual sequences (haplotypes) as described previously (Breyta et al. 2013). Sequence

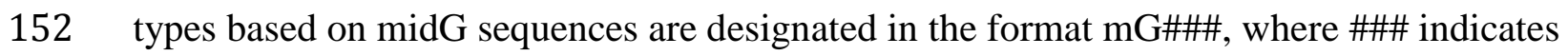

153 a randomly assigned 3 digit number that is specific to a sequence, and $\mathrm{U}, \mathrm{M}$, or $\mathrm{L}$ is

154 added at the end to indicate the major IHNV genogroup (e.g. type mG001U falls within

155 the $\mathrm{U}$ genogroup in phylogenetic analyses). Newly generated sequences and all 
156 previously known USD sequences detected in North American IHNV were used for

157 phylogenetic analysis. Taxa were individual sequences representing each midG

158 haplotype, associated with the first year of its detection. Phylogenetic analysis was

159 performed using coalescent Bayesian MCMC methods as implemented in the BEAST

160 software package v1.8.0 (Drummond et al. 2002; Drummond \& Rambaut 2007). Results

161 were analysed, annotated, and drawn using the complementary suite of programs,

162 including Tracer v1.5 and FigTree v1.3.1 (Rambaut \& Drummond 2003; Rambaut \&

163 Drummond 2007; Rambaut 2009). Dated taxa were used with a relaxed uncorrelated

164 lognormal molecular clock prior, with a gamma-distributed rate prior extrapolated from

165 the range of known error rates of RNA-dependent RNA polymerases (Drummond et al.

166 2006; Biek et al. 2006; Drummond \& Suchard 2010). The relaxed clock was used for the

167 midG analysis after it was confirmed that the strict clock could be rejected (95\%

168 confidence interval of the coefficient of variation and standard deviation of the relaxed

169 clock did not span zero) and the relaxed clock yielded a positive Bayes Factor in

170 comparison to the strict clock. No specific inferences were made directly from the

171 molecular clock parameter. The phylogenetic tree is derived from three separate MCMC

172 analyses of 150 million generations that each achieved convergence and good mixing,

173 and were subsequently combined, summarized, and analyzed.

\section{Results}

\section{$175 \quad 3.1$ Geographic and genetic scope of study}

176 Within the US, the Columbia River basin occupies large portions of Washington,

177 Oregon, Idaho, and Montana states. Washington and Oregon also have significant

178 numbers of smaller non-Columbia watersheds, those that drain directly to the Pacific

179 Ocean, that are also included in this analysis. Within this geographic region, a total of

$180 \quad 2,590$ isolates of IHNV collected from salmonid fish hosts between 1958-2014 have been

181 genetically typed (Table 1). Of these isolates, only $2 \%$ were detected before 1980, and

$18277 \%$ were detected during 2000-2014 (Figure 1). Even when corrected for sampling bias

183 by using only one representative of each virus detection event (see methods), 65\% of

184 typed cohorts were sampled between 2000-2014 (Figure 1). Of the 2590 isolates in this

185 study, 94\% originated from one of three major salmonid species: steelhead or rainbow

186 trout (O. mykiss, 44\%), Chinook salmon (O. tshawytscha, 32\%) or sockeye or kokanee 
187 salmon (O. nerka, 18\%). Virus isolates from Washington and Idaho states were 188 approximately equally distributed between either the $\mathrm{U}$ or $\mathrm{M}$ genogroup (Table 1). In 189 Oregon state, typed IHNV isolates were found in all three genogroups, though $\mathrm{U}$ was 190 more abundant than $\mathrm{M}$, and $\mathrm{L}$ detections were the great minority. Isolates from Montana 191 were the least numerous and consisted entirely of $\mathrm{U}$ group virus in kokanee salmon 192 (freshwater O. nerka).

193 Among the 2,590 isolates, there were 322 genetic types. Coalescent phylogenetic 194 analyses of these haplotypes revealed strong support for all previously described North 195 American IHNV genogroups and subgroups (Figure 2). U genogroup types were either 196 part of UC or UP subgroups. M genogroup types were primarily of MB, MC, and MD 197 subgroups, with small numbers of types in subgroups MA, ME, and MF. L genogroup 198 types were the least numerous. As expected from previous analyses, the L genogroup was 199 clearly monophyletic (posterior probability 0.97 ), and the U and $\mathrm{M}$ genogroups shared a 200 strongly supported common ancestral node (posterior probability 0.97 ). $\mathrm{U}$ genogroup taxa 201 formed a polytomy with this common ancestral node, while the $\mathrm{M}$ genogroup was 202 derived from that node as a monophyletic group (posterior probability 0.79 ). The larger 203 subgroups within the major genogroups were supported as follows: UC 0.89, MB 0.76, 204 MC 1.0, and MD 1.0. Smaller subgroup support values were MA 1.0, ME 1.0, and MF 2051.0

206 The phylogeny also revealed one previously unrecognized subgroup within the $\mathrm{M}$ 207 genogroup, designated 'MH' (Figure 2, asterisk). This new MH subgroup includes 208 several types previously described as part of the MN subgroup, but not all. The remaining 209 MN types do not form a well-supported clade, instead these types form a polytomy with 210 the ancestral node of the M genogroup. The MH subgroup had a posterior probability of

2110.86 and contained 7 taxa. The most commonly detected type in the MH subgroup was 212 type mG007M, which first appeared in 1980 and was associated with a significant 213 emergence in steelhead trout that involved disease outbreaks at many sites in the lower 214 Columbia region. This type was repeatedly detected until 1994, and was then displaced 215 by another dominant MD genotype (Breyta et al. 2013; Kell et al. 2014). The six 216 additional taxa in the MH subgroup were detected between 1981 and 1992, also in the 217 lower Columbia region. The overlapping geographic and temporal signal of these six 
218 types, along with their phylogenetic signal of high probability of relatedness to mG007M,

219 indicates that they are variants of mG007M. It was not previously known that type

$220 \mathrm{mG007M}$ produced genetic variants to a similar degree as later major types (Breyta et al.

221 2013).

2223.2 Complex patterns of IHNV viruses in Washington, Oregon, Idaho, and Montana

223 There was a temporal pattern in which the numbers of typed virus isolates, and the

224 bias-corrected numbers of virus-positive fish cohorts, peaked every 5-7 years (Figure 1).

225 There was a notable increase in the number of typed isolates and cohorts in 2002, and

226 another increase in the number of typed isolates in 2009 that corresponded to a more

227 gradual increase in the number of positive cohorts. The increase in numbers of positive

228 cohorts in 2002 was driven by samples originating from Columbia River basin

229 steelhead/rainbow trout and Chinook salmon (Figure 3 panels A and C). The increase in

2302009 was partially driven by isolates originating from coastal steelhead trout cohorts

231 (Figure 3, panel B), due to documented emergence events (Breyta et al., 2013). Peaks in

232 coastal sockeye salmon in 2011-2013 were also apparent (Figure 3). In general,

233 maximum years had high numbers of typed adult and juvenile cohorts, while minimum

234 years had low numbers of typed adult cohorts, and few or no typed juvenile cohorts

235 (Figure 3). This periodic pattern appeared in both $\mathrm{U}$ and $\mathrm{M}$ viruses, although the signal

236 was strongest for $\mathrm{U}$ viruses in Columbia River basin Chinook salmon and $\mathrm{M}$ viruses in

237 Columbia River basin steelhead/rainbow trout.

238 Geographic spread of M group IHNV was also apparent. Before 2004, there was only

239 one detection of M group IHNV outside the Columbia River basin, (Emmenegger et al.

240 2000; Breyta et al. 2013)(Figure 3B). Starting in 2004, M group IHNV emerged in

241 several coastal populations of Chinook salmon and steelhead trout. In coastal waters of

242 Oregon, type mG110M was found in Chinook salmon in 2004 and 2006, and in

243 steelhead/rainbow trout during 2005-2007. In the coastal waters of Washington, type

$244 \mathrm{mG} 110 \mathrm{M}$ (and its non-dominant variant type mG168M) was found in Chinook salmon

245 during 2007-2009 (Figure 3D), at the beginning of the larger emergence of types

$246 \mathrm{mG110M}$ and $\mathrm{mG139M}$ and their variants in coastal Washington steelhead trout during

247 2007-2011 (Breyta et al. 2013). In both coastal Oregon and coastal Washington the most 
248 significant impact of these emergence events in terms of juvenile fish disease occurred 249 mostly in steelhead/rainbow trout, not Chinook salmon (compare Figure 3B and D).

250 There was also a pattern of host specificity, apparent in all regions and all years.

251 Steelhead/rainbow trout in both the Columbia River basin and coastal/Puget Sound

252 waters had far more M group IHNV detected than U group, in both adult and juvenile

253 fish (Figure 3, top row, orange bars). Chinook and sockeye salmon both had far more U

254 group IHNV detected in fish of any age and in either region (Figure 3, middle and bottom

255 row panels). When Chinook salmon were found to have M group viruses it was most

256 commonly detected in asymptomatic adult fish and in years when large numbers of

257 sympatric steelhead trout cohorts had M group viruses, suggesting spillover from

258 steelhead trout. The same spillover pattern of $M$ viruses in sockeye salmon was evident in

259 the Columbia River basin. In addition to this broad pattern of host specificity, there was a

260 more nuanced pattern of host specificity among $U$ and $M$ subgroups that is described

261 below.

\section{$262 \quad 3.3$ Distribution of subgroups in the landscape}

263 Throughout the study landscape heterogeneity was evident in which IHNV subgroup

264 was predominant in each hydrobiological area, and the host species in which they were

265 most commonly found. The hydrological landscape can be divided by natural drainage

266 and by what virus subgroups were dominant, making 12 distinct regions (Figure 4 and

267 Table 2). Of these, only three regions had only $U$ or M subgroup viruses. Within the

268 Puget Sound, only UP subgroup viruses were found with one exception, detection of an

269 MH type in 1986 (region 12 in Figure 4A and Table 2). These Puget Sound UP viruses

270 were primarily detected in sockeye/kokanee salmon. The second region was the upper

271 Columbia River basin, which is defined as the portion of the watershed that is no longer

272 open to fish migration due to the barrier of Chief Joseph dam, including sites in both

273 Washington and Montana (region 4, Figure 4B). This region had a very low number of

274 typed cohorts, accurately reflecting a low number of positive cohorts overall. Viruses in

275 this area were also UP viruses, entirely in kokanee salmon (Table 2). The third region

276 with only one genogroup of IHNV was the upper Snake River region, which is similarly

277 restricted for fish migration due to Oxbow dam, and includes the intensive rainbow trout

278 farming industry in the Hagerman Valley (region 8, Figure 4A). In this region, only M 
279 subgroup viruses were detected, and it was the only area where all $7 \mathrm{M}$ subgroups have 280 been detected (Table 2) (Troyer \& Kurath 2003). Furthermore, all known detections of 281 MN types occurred in this region (Table 2). MN types are the most basal, least derived 282 members of the M group (Figure 2, red box) (Kurath et al. 2003). In the upper Snake, 283 detections of M subgroup viruses occurred primarily in rainbow trout and to a lesser 284 extent steelhead trout (Table 2).

285 Throughout the rest of the Columbia River basin, $\mathrm{U}$ and M subgroup viruses co286 occurred, and there were distinct patterns of which dominated where. The Columbia 287 River and its largest tributary, the Snake River, were each divided into middle and lower 288 sections, with a major tributary watershed in each (Figure 4B, Columbia River regions 12893 and Snake River is regions 5-7). The Columbia River regions 1 and 2 had the greatest 290 numbers of typed cohorts of any region in the current study, and contained the most viral 291 diversity. These regions were also the location of 52\% of all detections of MH subgroup 292 viruses (Figure 2). Comparing the four segments of the Columbia River, the burden of 293 IHNV (number of typed events) generally decreased moving upstream (Table 2). The 294 proportional presence of $\mathrm{U}$ viruses increased moving upstream, with UC viruses 295 increasing in prevalence from region 1 to 2 and predominating in the central two regions, 296 and UP viruses increasing between regions 3 and 4. At the same time the proportional 297 presence of MD viruses decreased moving upstream. In these regions, steelhead trout was 298 slightly more often positive than Chinook salmon. In contrast, sockeye salmon were the 299 least commonly positive in anadromous regions, but kokanee salmon (also O. nerka) was 300 the only positive host in the landlocked upper Columbia River, even though trout species, 301 including rainbow trout, exist in the landlocked waters as well.

302 Comparing the four Snake River regions (Table 2 regions 5-8), the greatest 303 prevalence of IHNV was in the lower Snake, and the lower three regions had similar 304 subgroups of viruses detected. However, the proportional presence of UC decreased 305 moving upstream, and the proportional presence of MB and MC increased moving 306 upstream. Within the lower three regions of the Snake River, Chinook salmon were the 307 most commonly positive, while the majority of isolates in the upper Snake River were 308 from rainbow trout. 
The coastal regions are divided into south and north Oregon coasts and the

310 Washington coast (regions 9-11, respectively, in Figure 4B and Table 2). The south

311 Oregon coast had very few typed positive cohorts, all of which originated from Chinook

312 salmon. Among these cohorts, L genogroup was most common, but there was one

313 detection of UC subgroup virus. No L group viruses were detected in the north Oregon

314 coast, but UC and MD viruses were found in a 3:1 ratio. The host species with these

315 viruses was mostly steelhead and rainbow trout, followed by Chinook salmon. The

316 Washington coast differed in that there were more typed cohorts (nearly $2 \mathrm{x}$ the two

317 Oregon coast regions combined) and there were no UC viruses detected. Instead,

318 Washington coast had a mix of MD and UP viruses, which were primarily found in

319 steelhead trout and sockeye salmon, respectively. The MD virus detections in the

320 Washington coast region were twice as common as UP detections, due to the emergence

321 of these viruses between 2007-2011 (Breyta et al. 2013).

322 In all 9 regions where $\mathrm{U}$ and $\mathrm{M}$, or $\mathrm{U}$ and $\mathrm{L}$ genogroup viruses co-existed, only two

323 subgroups were observed in the majority of events, despite all seven $\mathrm{U}$ or M subgroups

324 being detected at some time (Figure 4B, regions 1-3, 5-7, 9-11). Furthermore, within each

325 region the two dominant subgroups were never found in equal proportions. Instead, one

326 subgroup was found in an average of $75 \%$ of detections (range $67-89 \%$ ) while the second

327 was in an average of $20 \%$ of detections (range 6-33\%), a 3.5-fold difference (Figure 4G).

328 In all cases, the hydrobiological region where each subgroup formed the primary

329 proportion was adjacent to the region where it was the secondary dominant proportion

330 (Figure 4C-F).

\section{$331 \quad 3.4$ Host specificity of subgroups}

332 While the general host specificity of $\mathrm{U}$ and $\mathrm{M}$ genogroups was consistent with 333 previous reports, greater detail was evident for the five dominant $\mathrm{U}$ and $\mathrm{M}$ subgroups.

334 Here host specificity was measured as natural field incidence, or the proportion of each

335 subgroup detected in different host species in cohorts of any age fish (Table 3). This was

336 also refined by considering only detections in juvenile fish as a proxy for disease (Table

337 3). The three $\mathrm{M}$ subgroups $\mathrm{MB}, \mathrm{MC}$, and $\mathrm{MD}$ all occurred predominantly in $O$. mykiss

338 hosts, but differed in which host life history types (migratory steelhead trout or

339 freshwater rainbow trout, both $O$. mykiss) were infected most often. Within subgroups 
$340 \mathrm{MB}$ and MC, $82 \%$ and $79 \%$ of all detections, respectively, occurred in rainbow trout,

341 with similar proportions when only detections in juvenile fish were considered. In

342 contrast, $71 \%$ of all MD subgroup viruses were found in steelhead trout, and $77 \%$ of MD

343 viruses from juvenile fish were also in steelhead trout (Table 3). None of the three M

344 subgroups were detected in significant numbers of events (either all fish or juvenile fish)

345 in sockeye salmon $(1 \%, 0 \%)$ or Chinook salmon $(13 \%, 2 \%)$, although spillover of $\mathrm{M}$

346 subgroup types was more common in Chinook salmon than in sockeye/kokanee salmon

347 (Table 3).

348 In contrast, the U subgroups UP and UC were not specific for the O. mykiss host 349 species. The detection of UP types was most common in sockeye and kokanee salmon,

350 with only rare ( $<7 \%$ in detections of any age fish, $<2 \%$ of juvenile fish) detections in

351 steelhead/rainbow trout or Chinook salmon. Appearance of UC types was primarily in

352 Chinook salmon $(62 \%, 59 \%)$, but a large proportion of UC viruses were also found in

353 steelhead $(30 \%, 30 \%)$, and only a small proportion was detected in sockeye/kokanee

354 salmon $(5 \%, 6 \%)$ (Table 3). Thus the two U subgroups differed in host species

355 specificity, with the UC subgroup being unique among the five dominant U or M

356 subgroups in occurring in relatively high abundance in two different host species.

\section{$357 \quad 3.5$ Dominant virus types}

358 Among the genetic types detected, several dominant types were identified that were

359 widely detected in time and space. Among the $160 \mathrm{U}$ group virus types, 8 types (6\%)

360 were responsible for $72 \%$ of all detection events (Figure 5A). Similarly among the 139

361 detected $M$ group virus types, 7 types (5\%) were responsible for $60 \%$ of all detection

362 events (Figure 6A).

363 Within U genogroup, there were 5 dominant UC virus types and 3 dominant UP types

364 that were each detected in 5 or more years, and at 5 or more sites (Figure 5A). In both

365 subgroups there was a general temporal pattern of the older dominant types being

366 detected for many years and continuing concurrently with more recently emerged

367 dominant types (Figure 5B). Among UC viruses, type mG001U has been detected in a

368 total of 28 years between 1973-2011. These detections are dispersed throughout the

369 hydrobiological range of UC viruses (Figure 4C). Type mG032U was first detected in

3701988 so its temporal range falls entirely within that of mG001U (Figure 5B), and its 
371 geographic range is almost as dispersed. The three remaining dominant UC types were all

372 first detected in 2005 and have been detected every year since (Figure 5B). Types

$373 \mathrm{mG} 147 \mathrm{U}$ and $\mathrm{mG174U}$ were first detected in the lower Snake region (Figure 4A, region

374 5) and have remained there, dominating detections there and in the middle Snake, with

375 one exception for each type. Type mG147U was detected once in the north Oregon coast

376 in 2007, and type mG174U was detected in the same region in 2011, both in adult

377 Chinook salmon. In the lower Snake region, type mG174U and numerous

378 phylogenetically related variants (Figure 2, orange box) are more commonly detected

379 than mG147U and its variants (Figure 2, blue box). Type mG151U was first detected in

380 the Salmon River region (Figure 4A, region 7) in 2005. This type and its variants (Figure

3812 , yellow box) became the dominant UC type in the lower and middle Columbia River

382 region (Figure 4A, regions 2-3), with continued but sporadic detections in the middle

383 Snake River region (Figure 4A, region 6). These three more recently emerged UC types

384 had smaller geographic footprints than the older dominant UC types, and with only two

385 exceptions they were limited to the range where UC is dominant (Figure 4C).

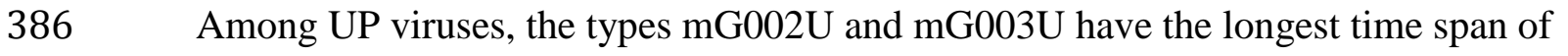

387 detection, beginning in 1984 and 1974, respectively (Figure 5B). They also have the

388 widest geographic dispersal, being detected in Puget Sound and the Washington coast,

389 and also beyond the study area in Alaska and British Columbia (Kurath et al., 2003; K.

390 Garver, pers. comm.). Type mG050U was first detected in 1988 in the middle Columbia

391 River region, and was not detected again until 2009-2013 when it emerged and became

392 dominant in the Puget Sound and Washington coast regions. One additional UP type,

$393 \mathrm{mG} 265 \mathrm{U}$, first emerged in 2012 and has since been detected in 2013-2014 at a total of 9

394 sites. While this means that type $\mathrm{mG} 265 \mathrm{U}$ does not yet meet the aforementioned

395 dominant type criteria, it is included here because it continues to be detected in 2015

396 (data not shown), and it has a uniquely broad host distribution that suggests it may

397 become dominant. Type $\mathrm{mG} 265 \mathrm{U}$ has been detected in six different species/types of

398 Pacific salmonids (sockeye and kokanee salmon, Chinook salmon, rainbow and steelhead

399 trout, and chum salmon), and in symptomatic juveniles of three of those species (sockeye

400 salmon, Chinook salmon, and rainbow trout). Out of all other known IHNV types, only

401 type $\mathrm{mG003U}$ has been detected in this broad distribution of species, with and without 
402 disease signs. However, type $\mathrm{mG} 003 \mathrm{U}$ attained this host distribution in a minimum of 23

403 years, while type $\mathrm{mG} 265 \mathrm{U}$ has done it in only 4 years, making it a genotype to be

404 monitored.

405 Within the $\mathrm{M}$ genogroup, there were 7 dominant types from 5 different subgroups that 406 were each detected in 4 or more years and at 5 or more sites (Figure 6B). These types

407 were dominant in two different regions, however. The dominant types of the upper Snake 408 River, types mG009M (MB), mG008M (MC), and mG010M (MA), were all detected 409 roughly concurrently, in the 1990s (Figure 6B), and almost exclusively detected in the 410 rainbow trout farming portion of the upper Snake River region 8. Genetic surveillance of 411 virus isolated from this region during 1980-1999 (Troyer et al. 2000; Troyer \& Kurath 412 2003) was 3-fold higher than during 2000-2014, so it is possible that these types have 413 continued to circulate but have not been sampled.

414 In contrast, types mG007M (MH), mG111M (MD) and mG110M (MD) were all 415 primarily detected in the lower Columbia and lowest Columbia/Willamette regions, but 416 they did not occur concurrently (Figure 4A). Instead, a pattern of serial emergence and 417 displacement was evident for these three types (Figure 6B) (Garver et al. 2003; Kell et al. 418 2014; Breyta et al. 2016a). A fourth dominant M type, mG139M (MD), also emerged in 419 the lower Columbia region in 2003 but did not displace mG110M there. All 4 of these 420 types also appeared outside the lower Columbia region, but only types mG110M and $421 \mathrm{mG139M}$ became dominant elsewhere. Type mG110M became dominant in steelhead 422 trout of the Oregon coast from 2005-2007 and of the Washington coast during 2007-

423 2009. Type mG139M became dominant in steelhead trout of the lower Snake region 424 during 2008-2010 (Breyta et al. 2016b), and in the Washington coast during 2010-2011, 425 apparently displacing mG110M there (Breyta et al. 2013). These virus types have been 426 extensively characterized for replication fitness, virulence, and infectivity as potential 427 drivers of viral displacement (Kell et al. 2014; Breyta et al. 2016a). More recently, there 428 were no M group IHNV types detected in 2014, echoing the submergence of $\mathrm{M}$ virus 429 detections during 2000-2001 (Figure 6B).

\section{$430 \quad 3.6$ Incidence of disease is not homogenous in the landscape}

431 While salmon and trout migrate throughout the freshwater environment, adult

432 populations eventually concentrate spatially to spawn, either at natural sites or hatcheries. 
433 Within the study area, genetic surveillance was conducted on samples from 252 unique

434 sites or complexes (a complex is a collection of discrete sites that are related by

435 management and fish movement, like a hatchery and its adult fish trap). Of these sites,

436231 (92\%) were a hatchery, complex, or fish farm, and non-hatchery/farm sites

437 comprised only $3 \%$ of the detection events in this report. Among all sampled sites in the

438 current study, virus was not uniformly detected. Ten sites comprised $26 \%$ of detections

439 with reported signs of IHN disease in juvenile fish, and each site had 10 or more cases of

440 juvenile disease. These ten hatchery or farm sites (4\% of collection sites) accounted for

$44131 \%$ of all detections and were designated 'focus sites' a-j (Figure 7). There was one

442 focus site in each Puget Sound, lower Snake, middle Snake River, north Oregon coast,

443 and lowest Columbia Willamette regions (Table 4). The lower Columbia River region

444 had two focus sites and the upper Snake River region had three focus sites, all of which

445 were rainbow trout farms that have not been sampled since 1998 (Table 4). For all but

446 one of the focus sites, the viruses detected correlated completely with the dominant virus

447 subgroup(s) and host types of their region (Table 4). The only exception was in the lower

448 Columbia River region, where more UC than MD viruses were detected, occurring in

449 steelhead trout and Chinook salmon. One of the two focus sites in this region only had

450 virus isolates from steelhead trout, and it had more MD than UC viruses, as is typical for

451 this host species (site e, Table 4).

\section{Discussion}

454 Genetic typing of viruses isolated over a period of 35 years from naturally occurring

455 IHNV infections in Pacific salmonid fish of the waters of Washington, Oregon, Idaho,

456 and Montana have revealed that IHNV is spatially, temporally, and ecologically diverse.

457 Despite the sympatric migration of multiple host fish species within the extensive

458 Columbia River basin, the heterogeneous nature and distribution of IHNV subgroups has

459 been maintained for decades. Only a few drivers of these patterns can be identified here, 460 leaving much to be learned.

461 The temporal heterogeneity in numbers of typed fish cohorts may indicate true

462 fluctuations in IHNV prevalence, but the possible contribution of surveillance biases

463 must also be considered. One kind of surveillance bias was identifiable in the current 
464 data, namely variable numbers of samples typed from positive fish cohorts. This was 465 controlled for by transforming the data into the numbers of positive cohorts instead of 466 numbers of virus isolates. This corrected for known cases of this surveillance bias, such

467 as the increase in the number of isolates typed in 2007-2009, during detailed investigation 468 of emergence events on the Washington coast (Breyta et al. 2013). A second kind of 469 surveillance bias would be variation in the number of fish cohorts sampled by the fish 470 health agencies over time. In general, agency testing has been consistent for adult fish 471 populations in our study area since the 1980s. Since adult fish cohorts comprise $84 \%$ of 472 the isolates in our data set we conclude that during 1980-2014 there was a reasonably 473 stable surveillance pressure overall, but this does not rule out changes from year to year 474 that may be important. Our knowledge, and thus our confidence in this assessment, is 475 highest during the more recent period from 2000-2014, allowing us to infer that the 476 temporal peaks observed in 2002-2004 and 2009-2011 reflected actual increases in field 477 prevalence of virus. Since temporal maximums and minimums occurred every 5-7 years 478 over the entire 34-year dataset, it is plausible that they represent real variations in IHNV 479 field prevalence. Drivers of these fluctuations may have included impacts on general fish 480 health from variation in natural factors like ocean conditions, stream conditions, or by 481 variations in anthropogenic factors associated with fish culture. The fact that minimum 482 years were characterized by having few or no positive juvenile cohorts and maximum 483 years had high numbers of both positive adult and juvenile cohorts, suggests that adults 484 were an infection source for juveniles. One possible driver of the temporal pattern in 485 adult fish is persistence of infection from the juvenile stage. However, since the saltwater 486 residence time for the three species differs slightly (2-3 years for sockeye salmon, 3-4 487 years for Chinook salmon, and 1-3 years for steelhead trout), and since all members of a 488 single juvenile cohort do not migrate back to spawn at the same time, this hypothesis is 489 difficult to assess under the current analysis. Future possible studies to better understand 490 the natural or anthropogenic factors that may have contributed to periodic increases in 491 IHNV prevalence and disease burden would inform management efforts to reduce IHN 492 disease and mortality.

493 Some level of spatial heterogeneity of IHNV, such as the punctate signals of highest 494 IHN disease incidence at hatcheries, is expected given the life history of fish as well as 
495 concentrating effect of hatcheries. In addition, the majority of surveillance in this report

496 is hatchery-based, and wild fish are under-sampled in this study. What is not clear is why

497 only $4 \%$ of hatcheries in this study account for $26 \%$ of all reported IHN disease events. If

498 factors at these specific sites that contributed to this signal can be identified, such as the

499 number of species reared, the size of the programs, or water supply conditions, then

500 targeted strategies for overall improvements to IHN disease burden can be developed. A

501 recent example of this was the successful reduction of IHN disease in steelhead trout at a

502 national hatchery when it was shown that delaying exposure of young fish to river water

503 avoided the primary transmission source of IHNV disease (Breyta et al. 2016b).

504 The drivers of spatial heterogeneity of virus subgroups may also stem in part from

505 hydrological ranges of fish species, as the different subgroups have distinctly different

506 host affinities. For example, the number of sockeye/kokanee salmon populations are

507 greatest in the Washington coast, Puget Sound, and the upper Columbia River basin, and

508 it is in these regions that the UP subgroup is dominant. Therefore the sockeye/kokanee

509 may maintain UP incidence at higher levels in those regions, even in the coastal regions

510 where Chinook salmon and steelhead trout are also found. The numbers of

511 sockeye/kokanee salmon populations are next most numerous in the middle Columbia

512 River region, where UP viruses were found but to a lesser extent than were UC viruses.

513 The number of sockeye or kokanee salmon populations are fewest in the lower segments

514 of the Columbia River and the Snake River regions 5-7, and the species is not found at all

515 in the Oregon coast regions. These regions had no detections of UP viruses, instead

516 viruses of the UC and MD subgroups were dominant. It is not clear if the high numbers

517 of populations of Chinook salmon and steelhead/rainbow trout in these regions means

518 that their UC and MD viruses suppressed UP incidence, or if other factors are more

519 important.

520 The differences between the U virus subgroups in the coastal Washington and north

521 coastal Oregon regions may be driven by host species distribution as well. Viruses of UC

522 subgroup only occurred in coastal Oregon where there are nearly no sockeye/kokanee

523 salmon. There were no UC viruses detected in coastal Washington despite the presence of

524 their most common host species, Chinook salmon and steelhead trout. However, since

525 sockeye/kokanee salmon are present in coastal Washington, it may be that UP viruses 
526 circulating in coastal Washington, and occasionally detected in Chinook salmon,

527 protected those fish from infection with UC viruses. Laboratory studies show that IHN

528 viruses from each subgroup can infect each of these major host species, and these

529 infections can trigger cross-protective immune responses (Engelking \& Leong 1989;

530 LaPatra et al. 1993c; Corbeil et al. 2000; Garver et al. 2005; Kurath et al. 2010). This

531 protective phenomenon may only operate in the coastal waters where overall burden of

532 IHNV is relatively low because UP viruses do not seem to have a protective effect for

533 local Chinook salmon in the mid-Columbia region, where Chinook salmon are more

534 frequently found to have UC viruses. As a caveat to this interpretation that applies to the

535 absence of any subgroup throughout this study, it is possible that low levels of UC in

536 coastal Washington or UP in coastal Oregon may have occurred undetected.

537 Another feature of the North coastal Oregon region 10 is that it was affected by the

538 same 'tide' of M group IHNV emergence that occurred in coastal Washington in 2007.

539 However, it occurred slightly earlier, caused fewer juvenile infections, and involved the

540 emergence of only one MD type (mG110M) instead of the three (types mG111M,

$541 \mathrm{mG} 110 \mathrm{M}$, and $\mathrm{mG139M}$ ) observed in coastal Washington. These three types first

542 emerged in the Columbia basin, and of the three, type mG110M was the most widely and

543 frequently detected (Breyta et al. 2013; Breyta et al. 2016a). The detection of only type

$544 \mathrm{mG110M}$ in coastal Oregon waters might imply that only the most prominent MD type

545 was able to emerge there, or it may be due to regional differences in surveillance, or

546 mechanism(s) that make the fish of Washington and Oregon coasts different, such as

547 different marine migration patterns.

548 One factor that may have influenced the distribution of subgroups within the

549 Columbia River basin was the anthropogenic impacts of dams and fish farms.

550 Hydroelectric dams installed between 1955-1961 completely block natural fish migration

551 from the two most inland reaches of the Columbia River basin (regions 4 and 8). In these

552 regions the distribution of IHNV subgroups was the most limited. In the upper Columbia

553 region 4 the only viruses detected were UP viruses, and in the upper Snake region 8, only

554 M subgroup viruses were detected. Since UP viruses were also detected in the adjoining

555 middle Columbia region 3, it is possible that the presence of UP viruses in kokanee

556 salmon of the upper Columbia region 4 predated the dams that now prevent anadromous 
557 ocean migration. This is consistent with current theory that $\mathrm{U}$ group IHNV in sockeye

558 salmon is the ancestral virus:host relationship (Kurath et al. 2003). The same could have

559 occurred in the upper Snake region 8, except that this region has very few kokanee

560 salmon populations (which are monitored for IHNV, and not found infected to date) but

561 is home to intensive rainbow trout farming. Given this dramatic man-made shift in host

562 availability, it is possible that the vast expansion of M group IHNV in that area displaced

563 U group IHNV below surveillance detection limits.

564 Emergence patterns of the specific dominant virus types differed among subgroups.

565 Comparing the three subgroups for which surveillance data was most consistent over

566 time, dominant MD viruses demonstrated a serial pattern of emergence and displacement,

567 while UC and UP viruses did not. Instead, dominant UP and UC viruses tended to persist

568 for a very long time throughout the hydrobiological range of the subgroup, and newer

569 dominant types displaced older types only on a local scale, within specific

570 hydrobiological regions. For instance, type $\mathrm{mG174U}$ is a UC type that largely displaced

$571 \mathrm{mG001U}$ within the lower Snake region 5, and type mG151U largely displaced mG001U

572 in the lower and middle Columbia regions 2-3. Since the analysis here revealed that UC

573 subgroup viruses have a larger footprint than MD, this may allow UC types looser

574 competitive constraints. Similarly the selection pressures for UP viruses may be different

575 than those of MD viruses, due to their extensive range that includes the fish of British

576 Columbia, Alaska, and Russia, suggesting that UP viruses may transmit across oceanic

577 ranges more successfully than UC or MD viruses (Kurath et al. 2003; Rudakova et al.

578 2007).

579 In addition to landscape-level differences, there were interesting differences apparent

580 in the ecological strategies demonstrated by UP, UC, and MD subgroup viruses inferred

581 from host species affinities of natural infections. Theory suggests that pathogens fall on a

582 specialist-generalist continuum of host species affinity, utilizing different benefits and

583 costs associated with each end of the spectrum. In practical terms, specialist viruses are

584 most fit and occur predominantly in a single host species, while generalist viruses

585 maintain fitness and occur in more than one host species (Remold 2012; McGee \&

586 Remold 2013) . Both UP and MD subgroups displayed high fidelity for a single host

587 species, while UC viruses frequently infected two host species (Table 3). The percent 
588 distribution of detection events among the three hosts $O$. nerka: $O$. tschawystcha: $O$.

589 mykiss was 87:7:7 for UP viruses, and 1:13:86 for MD viruses. In contrast, the percent

590 distribution among the same species was 6:62:32 for UC viruses. If we consider only

591 detection events in juvenile fish where disease impacts occur, the ratios are similar, with

592 90:2:7 for UP, 0:2:98 for MD, and 5:59:30 for UC. This clearly shows that UP viruses are

593 specialists for $O$. nerka, MD viruses are specialists for $O$. mykiss, and UC viruses are

594 generalists that access both $O$. mykiss and O. tshawytscha. One implication of this is that

595 steelhead trout suffer disease caused by viruses of two different subgroups, MD and UC,

596 while sockeye salmon and Chinook salmon are affected by viruses of only one subgroup.

597 Another implication is that the selective pressures on the more generalist UC viruses are

598 likely to be different than those acting on UP and MD viruses, which may be detectable

599 via future genetic analysis. Analyses of complete genomes of specific isolates from each

600 of these lineages may reveal more and is currently underway.

601 These results reveal that IHNV exists in the freshwater environment of the Columbia

602 River basin and surrounding watersheds in a complex patchwork of spatial dominance,

603 host species affinity, and temporal fluctuation. While it is likely that these complex

604 patterns are due to a combination of natural host-pathogen dynamics, anthropogenic

605 factors, and ecological conditions like climate and water quality, the relative influence of

606 any one factor is unknown. Since anthropogenic factors can potentially be changed to

607 benefit fish health in a directed, reasoned way, elucidating more about how the numerous

608 contributing factors drive patterns in IHNV incidence is a promising way to provide

609 direction for future management changes.

\section{Acknowledgements}

612 This work was supported by the U.S. Geological Survey (USGS), the U.S. Fish and

613 Wildlife Service (USFWS) FONS program, and USDA grant 2012-67015-19960 as part

614 of the joint USDA-NSF-NIH Ecology and Evolution of Infectious Disease program. The

615 funders had no role in study design, data collection and analysis, decision to publish, or

616 preparation of the manuscript. Any use of trade, firm, or product names is for descriptive

617 purposes only and does not imply endorsement by the U.S. Government.

618 
620 Table 1. Geographic, temporal, genetic, and species distributions of IHNV isolates in this 621 report.

622

\begin{tabular}{|c|c|c|c|c|c|}
\hline \multicolumn{6}{|c|}{$\begin{array}{l}\text { \# isolate } \\
\text { (\#cohorts) }\end{array}$} \\
\hline $\begin{array}{l}\text { State of } \\
\text { origin }^{\mathrm{a}}\end{array}$ & Year span & $\mathrm{U}$ & $\mathrm{M}$ & $\mathrm{L}$ & $\begin{array}{l}\text { Hosts most } \\
\text { commonly positive }\end{array}$ \\
\hline Washington & $1973-2014$ & $\begin{array}{l}445 \\
(275)\end{array}$ & $\begin{array}{c}402 \\
(175)\end{array}$ & $\begin{array}{c}0 \\
(0)\end{array}$ & $\begin{array}{l}\text { Steelhead/rainbow trout, } \\
\text { Chinook salmon, } \\
\text { sockeye/kokanee salmon }\end{array}$ \\
\hline Idaho & $1972-2014$ & $\begin{array}{c}491 \\
(153)\end{array}$ & $\begin{array}{c}472 \\
(210)\end{array}$ & $\begin{array}{c}0 \\
(0)\end{array}$ & $\begin{array}{l}\text { Steelhead/rainbow trout, } \\
\text { Chinook salmon }\end{array}$ \\
\hline Oregon & $1958-2014$ & $\begin{array}{l}310 \\
(235)\end{array}$ & $\begin{array}{c}138 \\
(105)\end{array}$ & $\begin{array}{c}17 \\
(11)\end{array}$ & $\begin{array}{l}\text { Steelhead/rainbow trout, } \\
\text { Chinook salmon }\end{array}$ \\
\hline Montana & 2014-2015 & $\begin{array}{c}2 \\
(2)\end{array}$ & $\begin{array}{c}0 \\
(0)\end{array}$ & $\begin{array}{c}0 \\
(0)\end{array}$ & Kokanee salmon \\
\hline
\end{tabular}

623

624

625 a There were 195 isolates of unknown state or province origin. Isolates from Washington 626 state may originate within the Columbia River basin or from coastal or Salish Sea 627 watersheds. Isolates from Oregon may originate within the Columbia River basin or from 628 coastal watersheds.

629 b 'cohorts' reflect bias correction to show the number of typed positive fish cohorts rather 630 than the number of typed isolates (see methods). 
Table 2. Hydro-biological range and host species distribution of major $\mathrm{U}$ and $\mathrm{M}$ subgroups. Number of typed events is shown, from a total of 2590 isolates collected between 1958-2014.

\begin{tabular}{|c|c|c|c|c|c|c|c|}
\hline \multirow[b]{2}{*}{$\begin{array}{l}(\text { map \#) } \\
\text { Hydro-biological } \\
\text { region }^{\text {a }}\end{array}$} & \multirow[b]{2}{*}{$\begin{array}{c}\# \\
\text { events }^{b}\end{array}$} & \multirow[b]{2}{*}{$\begin{array}{l}\text { subgroup, } \\
\text { (exceptions) }^{\mathrm{c}}\end{array}$} & \multirow[b]{2}{*}{ majority $^{\mathrm{d}}$} & \multicolumn{4}{|c|}{$\#$ cohorts per host species ${ }^{b}$} \\
\hline & & & & $\begin{array}{c}\text { Sockeye or } \\
\text { Kokanee salmon }\end{array}$ & $\begin{array}{l}\text { Chinook } \\
\text { salmon }\end{array}$ & $\begin{array}{l}\text { Steelhead } \\
\text { trout }\end{array}$ & $\begin{array}{c}\text { Rainbow } \\
\text { trout }\end{array}$ \\
\hline \multirow{4}{*}{$\begin{array}{l}1 \text { Lowest Columbia } \\
\text { and Willamette R }\end{array}$} & \multirow[t]{4}{*}{185} & MD & $71 \%$ & 1 & 24 & 89 & 18 \\
\hline & & $\mathrm{UC}$ & $20 \%$ & 3 & 12 & 19 & 3 \\
\hline & & MH & & 1 & 2 & 8 & 1 \\
\hline & & UP & & 1 & 2 & 1 & \\
\hline \multirow[t]{4}{*}{2 Lower Columbia R } & \multirow[t]{4}{*}{242} & UC & $72 \%$ & 19 & 92 & 61 & 3 \\
\hline & & MD & $25 \%$ & & 4 & 52 & 4 \\
\hline & & MH & & & & 5 & \\
\hline & & MB & & & 1 & 1 & \\
\hline \multirow[t]{4}{*}{3 Mid Columbia R } & \multirow[t]{4}{*}{57} & UC & $69 \%$ & 4 & 28 & 4 & \\
\hline & & UP & $33 \%$ & 8 & 7 & 4 & \\
\hline & & (MB) & & & & 1 & \\
\hline & & (MD) & & 1 & & & \\
\hline 4 Upper Columbia R & 5 & UP & $100 \%$ & 5 & & & \\
\hline \multirow{6}{*}{5 Lower Snake R } & \multirow[t]{6}{*}{246} & $\mathrm{UC}$ & $75 \%$ & \multirow{6}{*}{ n.s. } & 98 & 43 & 1 \\
\hline & & MD & $17 \%$ & & 7 & 22 & 3 \\
\hline & & $\mathrm{MH}$ & & & & 6 & \\
\hline & & MC & & & 3 & 2 & 1 \\
\hline & & UP & & & 2 & 1 & \\
\hline & & $(\mathrm{ME})$ & & & & 1 & \\
\hline \multirow[t]{5}{*}{6 Mid Snake R } & \multirow[t]{5}{*}{93} & $\mathrm{UC}$ & $86 \%$ & & 60 & 19 & 2 \\
\hline & & MD & $6 \%$ & & 1 & 4 & 1 \\
\hline & & MH & & n.s. & & 4 & \\
\hline & & $\mathrm{ME}$ & & & 2 & & \\
\hline & & (MB) & & & & 1 & \\
\hline \multirow[t]{6}{*}{7 Salmon R } & \multirow[t]{6}{*}{31} & $\mathrm{UC}$ & $71 \%$ & 3 & 17 & 2 & \\
\hline & & MB & $13 \%$ & & 2 & 1 & 1 \\
\hline & & $\mathrm{MC}$ & $7 \%$ & & 1 & 1 & \\
\hline & & (MD) & & & & 1 & \\
\hline & & (ME) & & & 1 & & \\
\hline & & $(\mathrm{MH})$ & & & & 1 & \\
\hline \multirow[t]{8}{*}{8 Upper Snake R } & \multirow[t]{8}{*}{69} & $\mathrm{MC}$ & $35 \%$ & & & 3 & 21 \\
\hline & & MB & $30 \%$ & & & 3 & 18 \\
\hline & & MD & & & & 2 & 6 \\
\hline & & MA & & & & & 7 \\
\hline & & MH & & n.s. & 1 & 2 & \\
\hline & & $\mathrm{ME}$ & & & & 1 & 1 \\
\hline & & MF & & & & & 2 \\
\hline & & $\mathrm{MN}$ & & & & & 2 \\
\hline \multirow[t]{2}{*}{9 S. OR Coast } & 9 & $\mathrm{~L}$ & $89 \%$ & & 8 & & \\
\hline & & $\mathrm{UC}$ & $11 \%$ & n.s. & 1 & & \\
\hline 10 N. OR Coast & 32 & MD & $75 \%$ & & 3 & 13 & 8 \\
\hline & & $\mathrm{UC}$ & $25 \%$ & n.s. & 3 & 5 & \\
\hline 11 WA Coast & 79 & MD & $67 \%$ & & 4 & 46 & 3 \\
\hline & & UP & $33 \%$ & 17 & 1 & 7 & 1 \\
\hline 12 Puget Sound & 95 & UP & $94 \%$ & 89 & 1 & & 1 \\
\hline & & UC & & 1 & 2 & & \\
\hline & & $(\mathrm{MH})$ & & & & & 1 \\
\hline
\end{tabular}

\footnotetext{
${ }^{a}$ See Figure 4 for map of hydro-biological regions. R, River.

${ }^{\mathrm{b}}$ Tally of total events and per species reflect $90 \%$ of all detections, remaining isolations occurred in Atlantic salmon, chum salmon, and coho salmon; n.s. no spawning population of host species present in this region.

${ }^{c}$ Exceptions are defined as 1 event; subgroups are listed in order of prevalence within each region.

${ }^{\mathrm{d}}$ majority is defined as the natural observed breakpoint of subgroup(s) that comprised $\geq 89 \%$ of typed cohorts.
} 
Table 3. Distribution of five dominant IHNV subgroups among host species.

\begin{tabular}{lccccc}
\hline & \multicolumn{5}{c}{ \# all events (\% of total), } \\
\# juvenile events (\% of total) \\
Host species ${ }^{\mathrm{a}}$ & $\mathrm{MB}$ & $\mathrm{MC}$ & $\mathrm{MD}$ & $\mathrm{UC}$ & $\mathrm{UP}$ \\
\hline O. nerka & $0(0)$, & $0(0)$, & $2(1 \%)$, & $31(6 \%)$, & $228(87 \%)$, \\
& $0(0)$ & $0(0)$ & $0(0)$ & $4(5 \%)$ & $37(90 \%)$ \\
O. mykiss-RT & $50(82 \%)$, & $48(79 \%)$, & $49(15 \%)$, & $10(2 \%)$, & $4(2 \%)$, \\
& $10(77 \%)$ & $11(65 \%)$ & $20(21 \%)$ & $4(5 \%)$ & $2(5 \%)$ \\
\multirow{3}{*}{ O. mykiss-ST } & $8(13 \%)$, & $9(15 \%)$, & $230(71 \%)$, & $154(30 \%)$, & $13(5 \%)$, \\
& $3(23 \%)$ & $6(35 \%)$ & $74(77 \%)$ & $22(30 \%)$ & $1(2 \%)$ \\
\multirow{3}{*}{ O. tshawytscha } & $3(5 \%)$, & $4(7 \%)$, & $43(13 \%)$, & $319(62 \%)$, & $18(7 \%)$, \\
& $0(0)$ & $0(0)$ & $2(2 \%)$ & $44(59 \%)$ & $1(2 \%)$ \\
\hline
\end{tabular}

${ }^{a}$ Oncorhynchus nerka (O. nerka) includes both sockeye salmon (anadromous) and kokanee salmon (non-anadromous) because these are similarly managed populations in fish hatcheries, while $O$. mykiss is separated into rainbow trout (O. mykiss-RT) and steelhead trout (O. mykissST) because these are, in general, differently managed populations, either fish farms or hatcheries, respectively. O. tshawytscha is Chinook salmon.

${ }^{b}$ the number of events in juvenile fish is shown separately as a general indicator of the incidence of disease events, which occur almost exclusively in juvenile fish. 
Table 4. Focus sites of high disease prevalence and relationship to virus occurrence within their hydrobiological regions.

\begin{tabular}{ccccc}
\hline & Focus site & & Hydro-biological region \\
Site $^{\mathrm{a}}$ & $\begin{array}{c}\text { Years } \\
\text { sampled }\end{array}$ & Virus subgroups \& hosts & $\begin{array}{c}\text { Region } \\
\#^{\mathrm{c}}\end{array}$ & Virus subgroups \& hosts $^{\mathrm{d}}$ \\
\hline $\mathrm{a}$ & $1984-2014$ & $\begin{array}{c}\text { UC > MD in } \\
\text { Chinook, steelhead }\end{array}$ & 5 & UC > MD in Chinook, steelhead \\
b & $1999-2013$ & UC > MD in Chinook & 6 & UC > MD in Chinook, steelhead \\
c & $1975-2014$ & UC in Chinook, steelhead & 2 & UC > MD in steelhead, Chinook \\
d & $1994-2014$ & UP in sockeye, coho & 12 & UP in sockeye \\
e & $1981-2013$ & MD > UC in steelhead & 2 & UC > MD in steelhead, Chinook \\
f & $1991-2008$ & MD > UC in & 1 & MD > UC in steelhead, Chinook \\
g & $1991-2014$ & $\begin{array}{c}\text { MD > UC in } \\
\text { steelhead/rainbow, Chinook }\end{array}$ & 10 & MD > UC in steelhead, rainbow \\
h & $1988-1998$ & MB, MC in rainbow & 8 & MC, MB in rainbow \\
i & $1982-1998$ & MB, MC in rainbow & 8 & MC, MB in rainbow \\
\hline j & $1988-1998$ & MB, MC in rainbow & 8 & MC, MB in rainbow \\
\hline
\end{tabular}

${ }^{\mathrm{a}}$ Focus sites a-j are as in figure 7

${ }^{\mathrm{b}}$ IHNV subgroup(s) that predominate at each focus site are shown. An inequality sign (>) indicates two subgroups are detected in unequal proportions at some sites, while other sites have two subgroups in similar proportions, or single subgroups. The two most common host species at each site are listed in order of frequency of virus detection; Chinook, Chinook salmon; steelhead, steelhead trout; coho, coho salmon; rainbow, rainbow trout; sockeye, sockeye salmon.

${ }^{c}$ hydrobiological region from figure 4 where the focus site is located

${ }^{\mathrm{d}}$ IHNV subgroup(s) that predominate in each hydro-biological region are shown, with proportions indicated as in footnote $b$ above. The two most commonly infected hosts in the region are shown (from table 2), in order of frequency of virus detection. 
640 Amend DF (1975) Detection and transmission of infectious hematopoietic necrosis virus 641 in rainbow trout. J Wildl Dis 11:471-478

642 Biek R, Drummond AJ, Poss M (2006) A virus reveals population structure and recent 643 demographic history of its carnivore host. Science 311:538-541

644 Bootland LM, Leong JC (1999) Infectious hematopoietic necrosis virus. In: Woo PTK, 645 Bruno DW (eds) Fish diseases and disordersCAB International, New York, pp 57-121

646 Breyta R, Jones A, Stewart B, Brunson R, Thomas J, Kerwin J, Bertolini J, Mumford S, 647 Patterson C, Kurath G (2013) Emergence of MD type infectious hematopoietic necrosis 648 virus in Washington State coastal steelhead trout. Dis Aquat Org 104:179 - 195, 649 DOI:10.3354/dao02596

650 Breyta R, McKenney D, Tesfaye T, Ono K, Kurath G (2016a) Increasing virulence, but 651 not infectivity, associated with serially emergent virus strains of a fish rhabdovirus. Virus 652 Evolution 2:vev018, DOI:10.1093/ve/vev018

653 Breyta R, Samson C, Blair M, Black A, Kurath G (2016b) Successful mitigation of viral 654 disease based on a delayed exposure rearing strategy at a large-scale steelhead trout 655 conservation hatchery. Aquaculture 450:213 - 224,

656 DOI:10.1016/j.aquaculture.2015.07.014

657 Corbeil S, LaPatra SE, Anderson ED, Kurath G (2000) Nanogram quantities of a DNA

658 vaccine protect rainbow trout fry against heterologous strains of infectious hematopoietic 659 necrosis virus. Vaccine 18:2817-2824

660 Drummond AJ, Ho SY, Phillips MJ, Rambaut A (2006) Relaxed phylogenetics and 661 dating with confidence. PLoS Biol 4:e88

662 Drummond AJ, Nicholls G, Rodrigo A, Solomon W (2002) Estimating mutation 663 parameters, population history and genealogy simultaneously from temporally spaced 664 sequence data. Genetics 161:1307-1320

665 Drummond A, Suchard M (2010) Bayesian random local clocks, or one rate to rule them 666 all. BMC Biology 8:114

667 Drummond A, Rambaut A (2007) BEAST: Bayesian evolutionary analysis by sampling 668 trees. BMC Evolutionary Biology 7:214

669 Emmenegger EJ, Troyer RM, Kurath G (2003) Characterization of the mutant spectra of 670 a fish RNA virus within individual hosts during natural infections. Virus Res 96:15-25 
671 Emmenegger EJ, Meyers TR, Burton TO, Kurath G (2000) Genetic diversity and 672 epidemiology of infectious hematopoietic necrosis virus in Alaska. Dis Aquat Organ 673 40:163-176

674 Engelking HM, Leong JC (1989) Glycoprotein from infectious hematopoietic necrosis 675 virus (IHNV) induces protective immunity against five IHNV types.

676 J Aquat Anim Health 1:291-300

677 Garver KA, LaPatra SE, Kurath G (2005) Efficacy of an infectious hematopoietic 678 necrosis (IHN) virus DNA vaccine in Chinook Oncorhynchus tshawytscha and sockeye 679 O. nerka salmon. Dis Aquat Organ 64:13-22

680 Garver KA, Troyer RM, Kurath G (2003) Two distinct phylogenetic clades of infectious 681 hematopoietic necrosis virus overlap within the Columbia River basin. Dis Aquat Organ $682 \quad 55: 187-203$

683 Groberg WJ (1983a) The status of viral fish diseases in the Columbia River Basin. In: 684 Leong JC, Barila T (eds) Proceedings of a Workshop on Viral Diseases of Salmonid 685 Fishes in the Columbia River Basin, Special PublicationBonneville Power 686 Administration, Portland, OR

687 Groberg WJ (1983b) Priority research needs concerning fish viruses prevalent among 688 Columbia River Basin salmonids. In: Leong JC, Barila TY (eds) Proceedings of a 689 Workshop on Viral Diseases of Salmonid Fishes in the Columbia River Basin, Special 690 PublicationBonneville Power Administration, Portland, OR, pp 159-167

691 Kell AM, Wargo AR, Kurath G (2014) Viral fitness does not correlate with three 692 genotype displacement events involving infectious hematopoietic necrosis virus. 693 Virology 464-465:146-155, DOI:10.1016/j.virol.2014.07.003 [doi]

694 Kelley GO, Bendorf CM, Yun SC, Kurath G, Hedrick RP (2007) Genotypes and 695 phylogeographical relationships of infectious hematopoietic necrosis virus in California, 696 USA. Dis Aquat Organ 77:29-40

697 Kurath G, Garver KA, LaPatra SE, Purcell MK (2010) Resistance and protective 698 immunity in redfish lake sockeye salmon exposed to $M$ type infectious hematopoietic 699 necrosis virus. Journal of Aquatic Animal Health 22:129

700 Kurath G, Garver KA, Troyer RM, Emmenegger EJ, Einer-Jensen K, Anderson ED 701 (2003) Phylogeography of infectious haematopoietic necrosis virus in North America. J 702 Gen Virol 84:803-814

703 LaPatra SE, Fryer JL, Rohovec JS (1993a) Virulence comparison of different 704 electropherotypes of infectious hematopoietic necrosis virus. Dis Aquat Org 16:115-120 
705

706

707

708

709

710

711 McGee LW, Remold SW (2013) Pleiotropic interactions involving virulence and

712 replication rate in experimentally evolved vesicular stomatitis virus. Evolutionary

713 Ecology Research 15:567

714 Meyers TR (1998) Healthy juvenile sockeye salmon reared in virus-free hatchery water

715 return as adults infected with infectious hematopoietic necrosis virus (IHNV): A case

716 report and review of controversial issues in the epizootiology of IHNV.

717 J Aquat Anim Health 10:172-181

718 Rambaut A (2009) http://tree.bio.ed.ac.uk/software/figtree/.

719 Rambaut A, Drummond AJ (2007) Tracer v1.4, Available from

720 http://beast.bio.ed.ac.uk/Tracer.

721 Rambaut A, Drummond AJ (2003) Tracer [computer program].

722 Remold S (2012) Understanding specialism when the jack of all trades can be the master

723 of all. Proceedings of the Royal Society of London B: Biological Sciences 279:4861-

$724 \quad 4869$

725 Rudakova SL, Kurath G, Bochkova EV (2007) Occurrence and genetic typing of

726 infectious hematopoietic necrosis virus in Kamchatka, Russia. Dis Aquat Organ 75:1-11

727 Troyer RM, Kurath G (2003) Molecular epidemiology of infectious hematopoietic

728 necrosis virus reveals complex virus traffic and evolution within southern Idaho

729 aquaculture. Dis Aquat Organ 55:175-185

730 Troyer RM, LaPatra SE, Kurath G (2000) Genetic analyses reveal unusually high

731 diversity of infectious haematopoietic necrosis virus in rainbow trout aquaculture. J Gen

732 Virol 81:2823-2832

733 Wolf K (1988) Infectious hematopoietic necrosis virus. In: Anonymous Fish viruses and

734 fish viral diseasesCornell University Press, Ithaca, NY, pp 83-114

735

736 


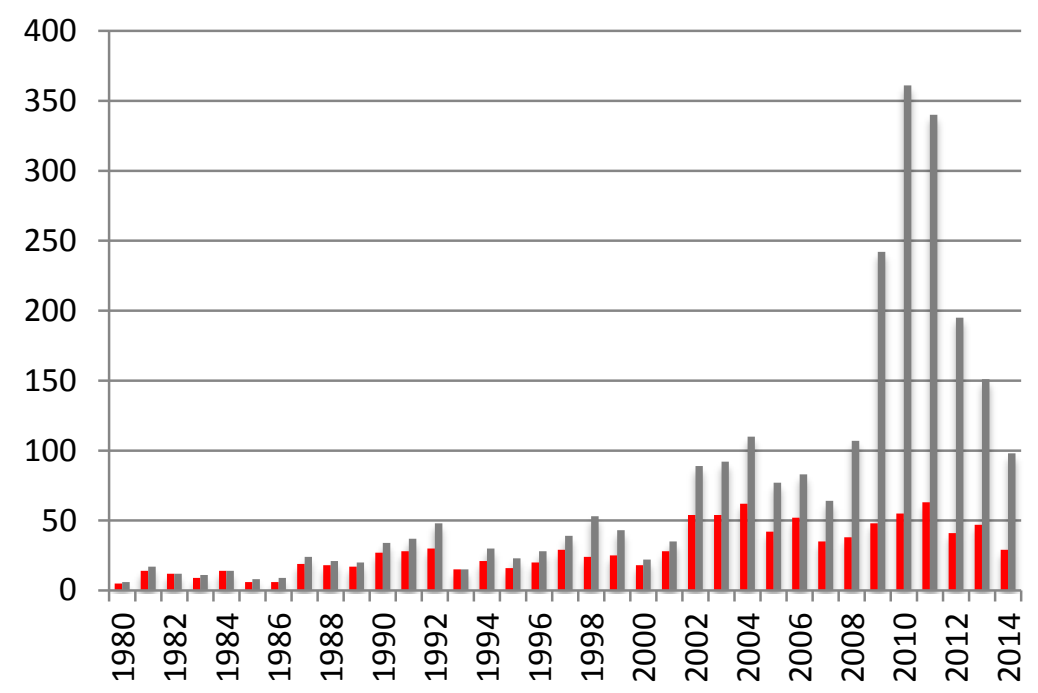

Figure 1. Number of typed isolates (grey) and cohorts (red) per year, 1980-2014. 


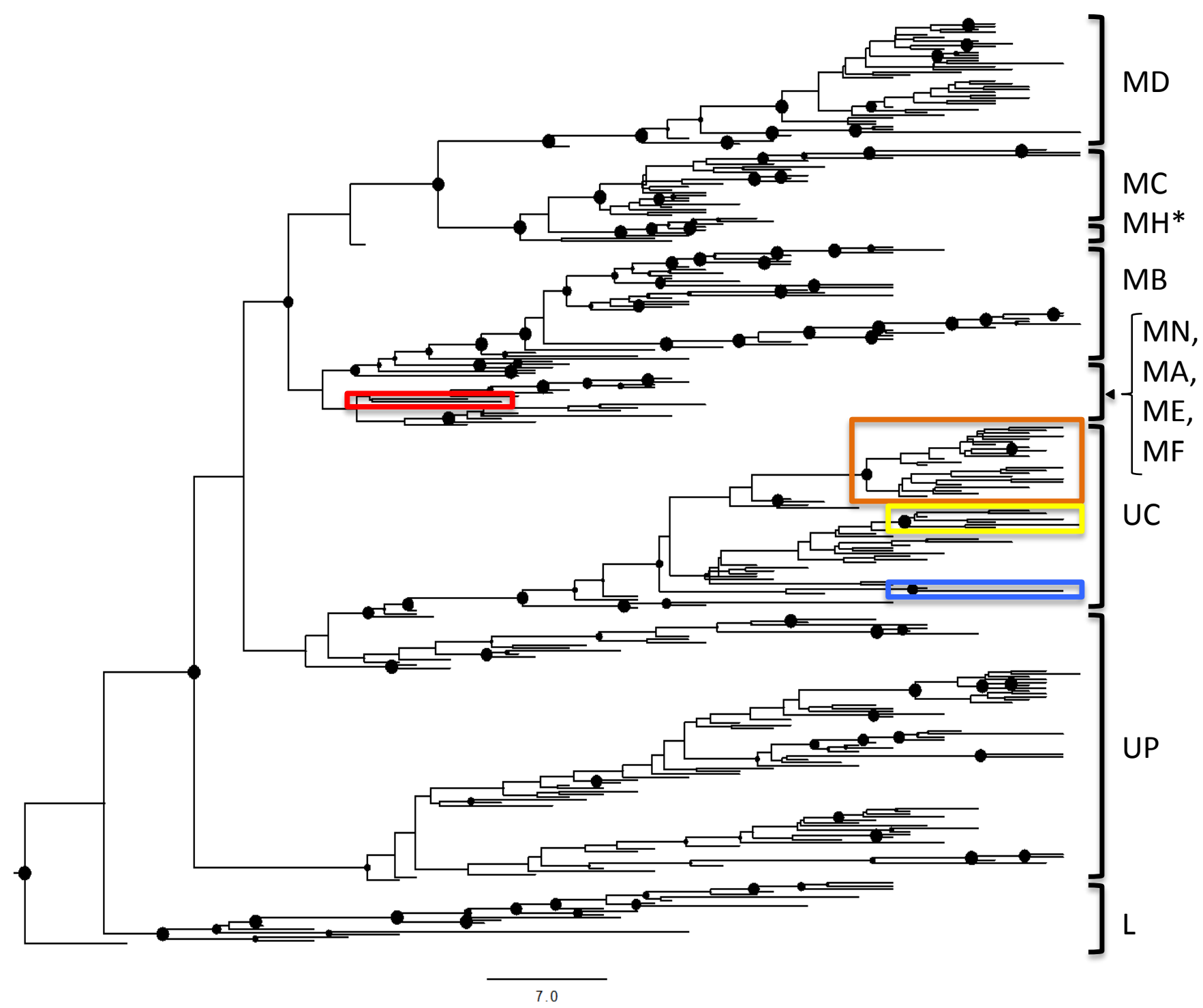

Figure 2. Coalescent phylogenetic analysis of all 322 currently known North American IHNV genetic types (haplotypes) based on the $303 \mathrm{nt}$ midG region. Branch lengths indicate substitutions/site/year, and circles at nodes are scaled so that the closer the posterior probability is to 1.0, the larger the circle; root node posterior probability is 1.0. Nodes with small circles should be interpreted as node-less branches polytomous at the next well-supported node to the left. Subgroups are bracketed and labeled at right, with the newly recognized subgroup $\mathrm{MH}$ indicated by an asterisk. Red box highlights the 7 taxa designated $\mathrm{MN}$, the $\mathrm{M}$ group taxa least derived from $\mathrm{M}$ group ancestral node. Specific dominant taxa and their variants are indicated by colored boxes: $\mathrm{mG174U}$ orange; $\mathrm{mG151U}$ yellow; mG147U blue. 

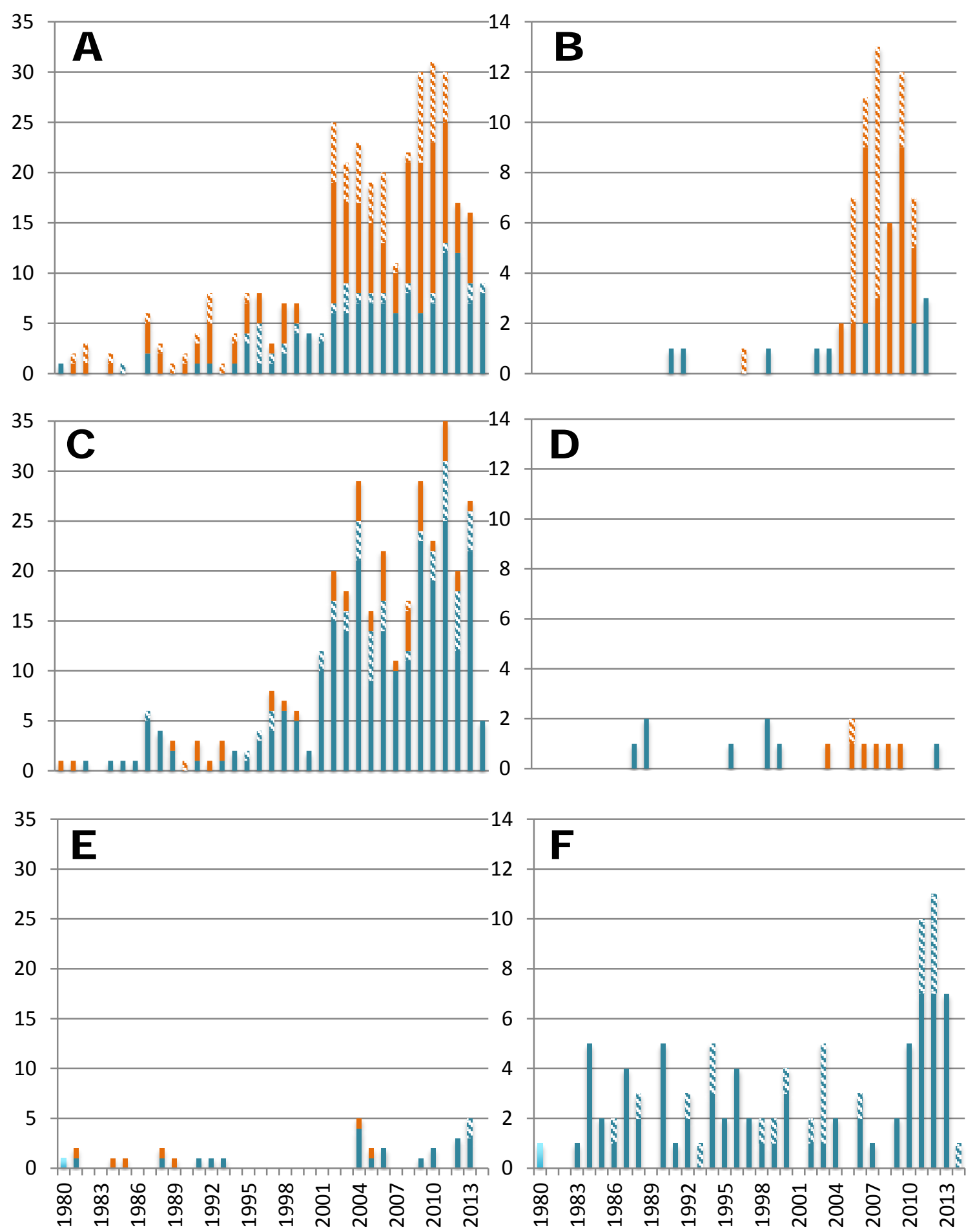

Figure 3. Number of typed IHNV positive cohorts of fish between 1980-2014. Detection of U (blue) or M (orange) genogroup IHNV types are shown in the three most common host species: steelhead/rainbow trout (top row, A-B); chinook salmon (middle row, C-D); or sockeye salmon (bottom row, E-F). Detection is indicated for adult (solid bars) or juvenile (hatched bars) fish in either the Columbia River basin (left, A, C, E) or coastal and Puget Sound waters (right, B, D, F), where there are fewer fish cohorts overall (note different axis scales in the two regions). 
A

British Columbia
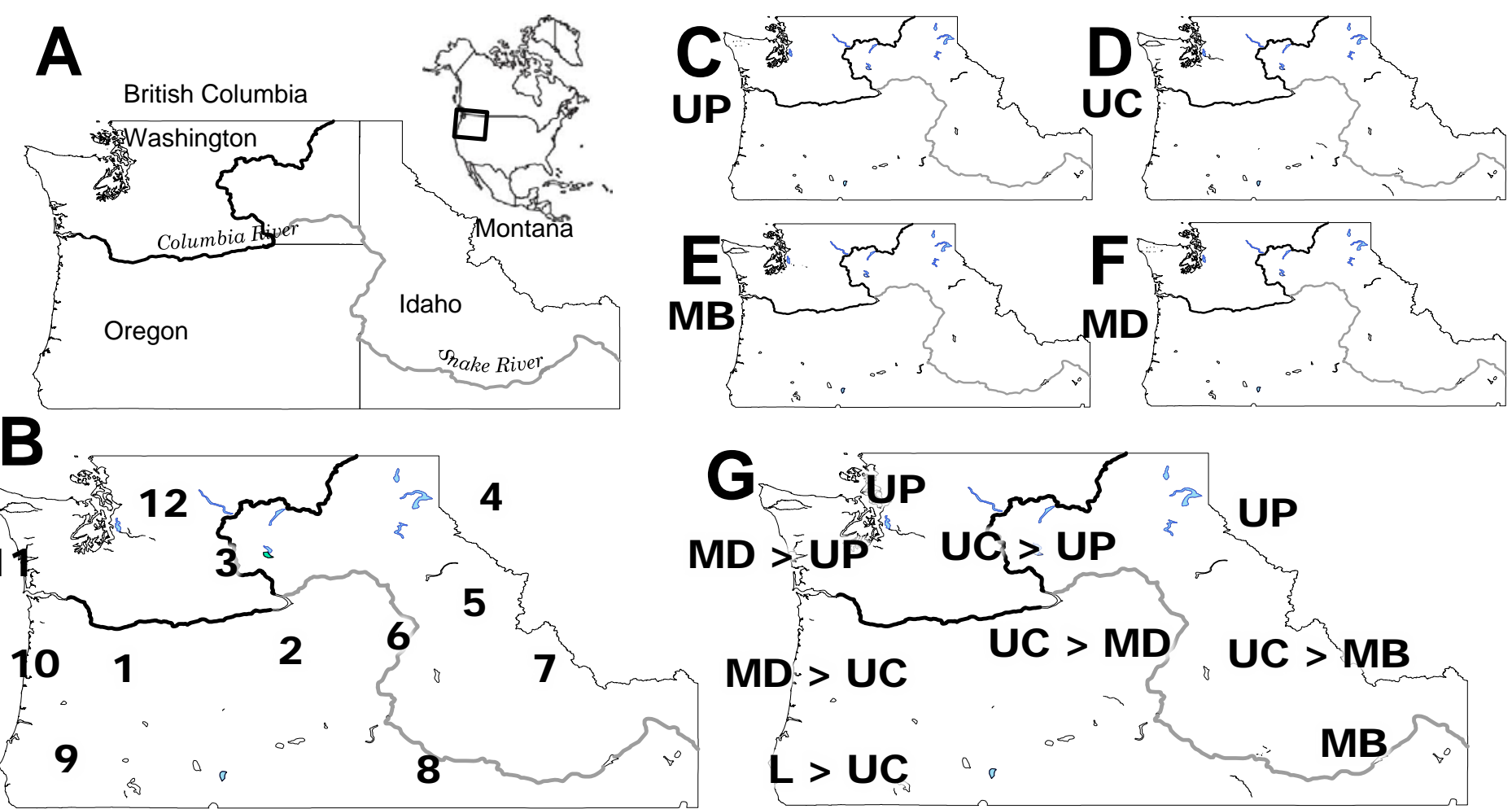

Figure 4. Rivers and hydrographic units of Washington, Oregon, and Idaho states. The Columbia and Snake Rivers are shown in heavy black, tributary rivers are shown in thin black. Hydrographic units delineate freshwater drainage and are color coded into hydro-biological regions first by shared drainage to either the Columbia River, the Snake River, or directly to the Pacific Ocean, and second by distribution of IHNV groups/subgroups. The uncolored regions are either arid and lack salmonid culture, or are watersheds not connected to the Columbia River basin. The Columbia River watershed includes portions of the Canadian British Columbia province, which lies across the northern border of WA state, and the US state of Montana which lies east of Idaho, so the map of the watershed goes over the state lines of WA and ID. A) Hydrobiological regions are as follows: 1 lowest Columbia River and Willamette, 2 lower Columbia River, 3 middle Columbia River, 4 upper Columbia River, 5 lower Snake River, 6 middle Snake River, 7 Salmon River, 8 upper Snake River, 9 south Oregon coast, 10 north Oregon coast, 11 Washington coast, and 12 Puget Sound. B-E) The four dominant subgroups of IHNV are shown in each panel, where the dark color indicates that subgroup is found in an average of $75 \%$ of detections and the light color indicates it is found in an average of $20 \%$ of detections. F) Bio-hydrographic regions are color coded and labeled for how the dominant IHNV subgroup(s) overlap. 

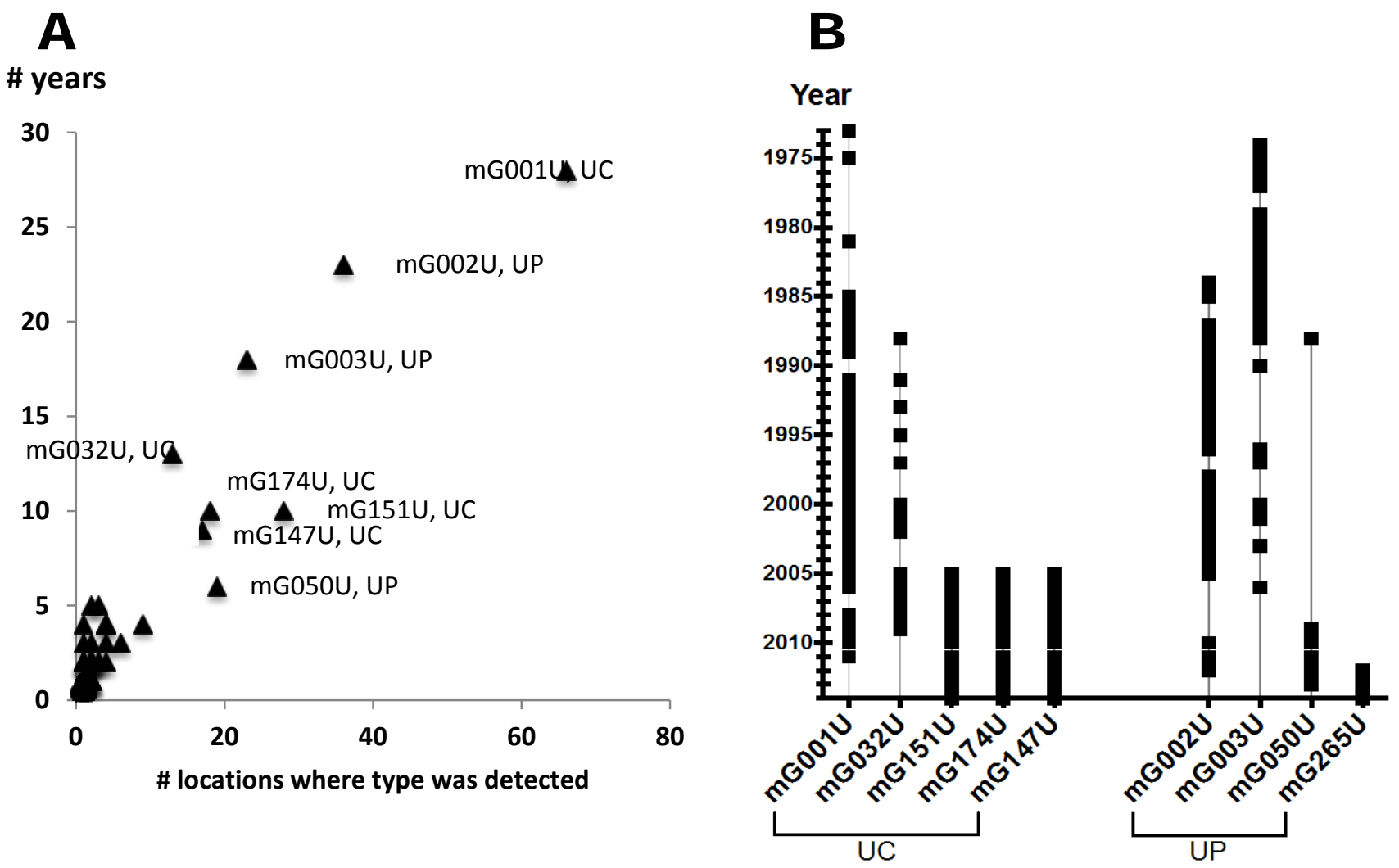

Figure 5. A) Temporal recurrence and spatial spread of $U$ genogroup virus types. Every type is indicated by a triangle; where many types have the same $x, y$ values the shape is heavier. The natural breakpoint used to define major types is detection in 5 or more sites and 5 or more years. B) Timeline of incidence of each of the 8 major types. Type $\mathrm{mG} 265 \mathrm{U}$ was detected in 9 locations and 3 years, but its temporal incidence is indicated in panel B. 


\section{A}

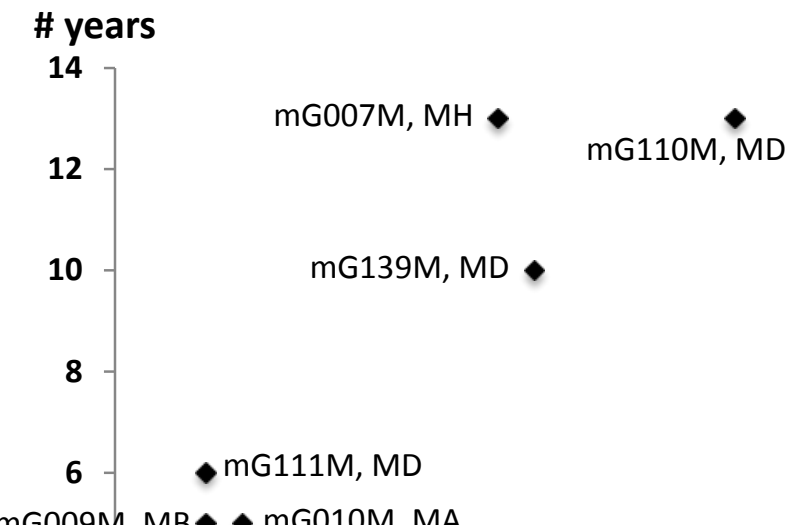

$\mathrm{mG} 009 \mathrm{M}, \mathrm{MB} \bullet \mathrm{mG} 010 \mathrm{M}, \mathrm{MA}$

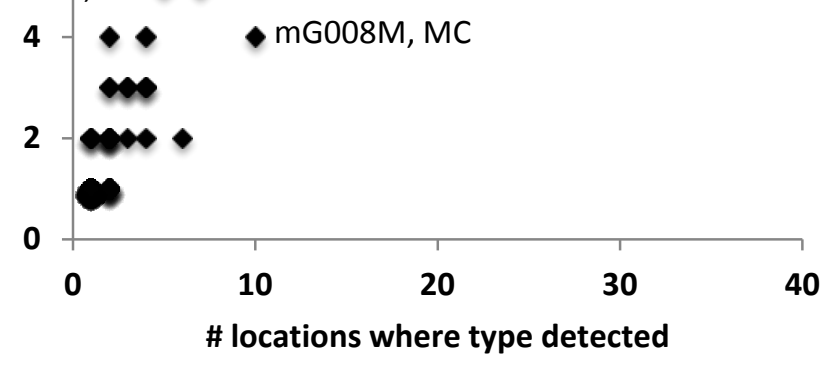

B

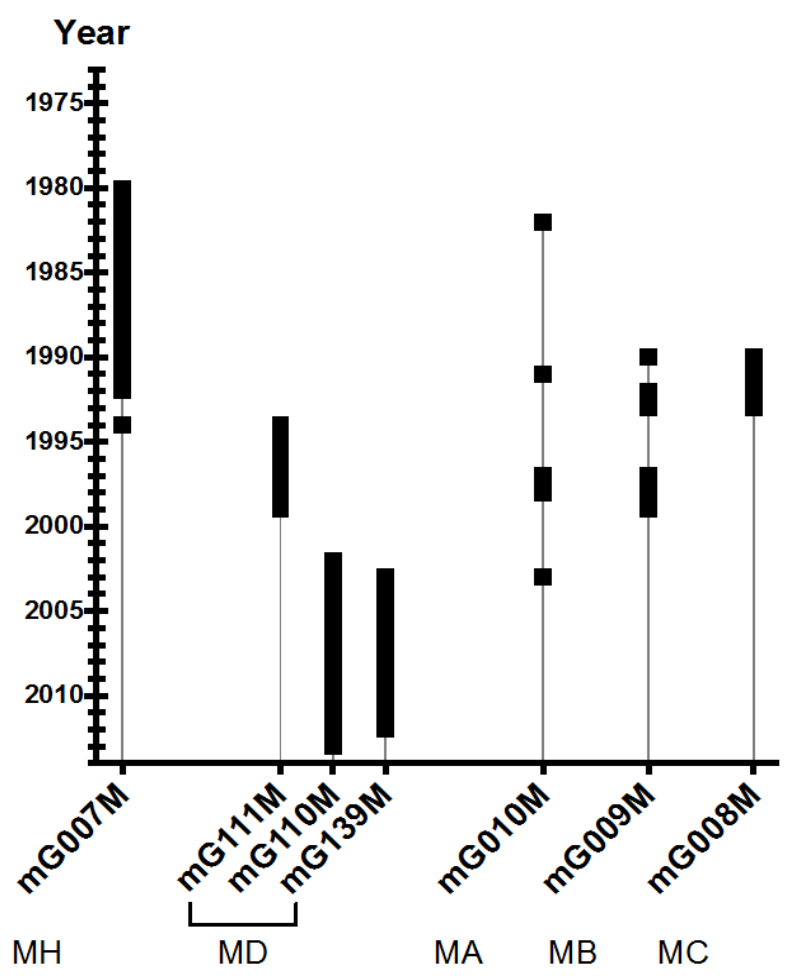

Figure 6. A) Temporal recurrence and spatial spread of $M$ genogroup virus types. Every type is indicated by a diamond; where many types have the same $x, y$ values the shape is heavier. The natural breakpoint used to define major types is detection in 5 or more sites and 4 or more years. B) Timeline of incidence of each of the 7 major types. 


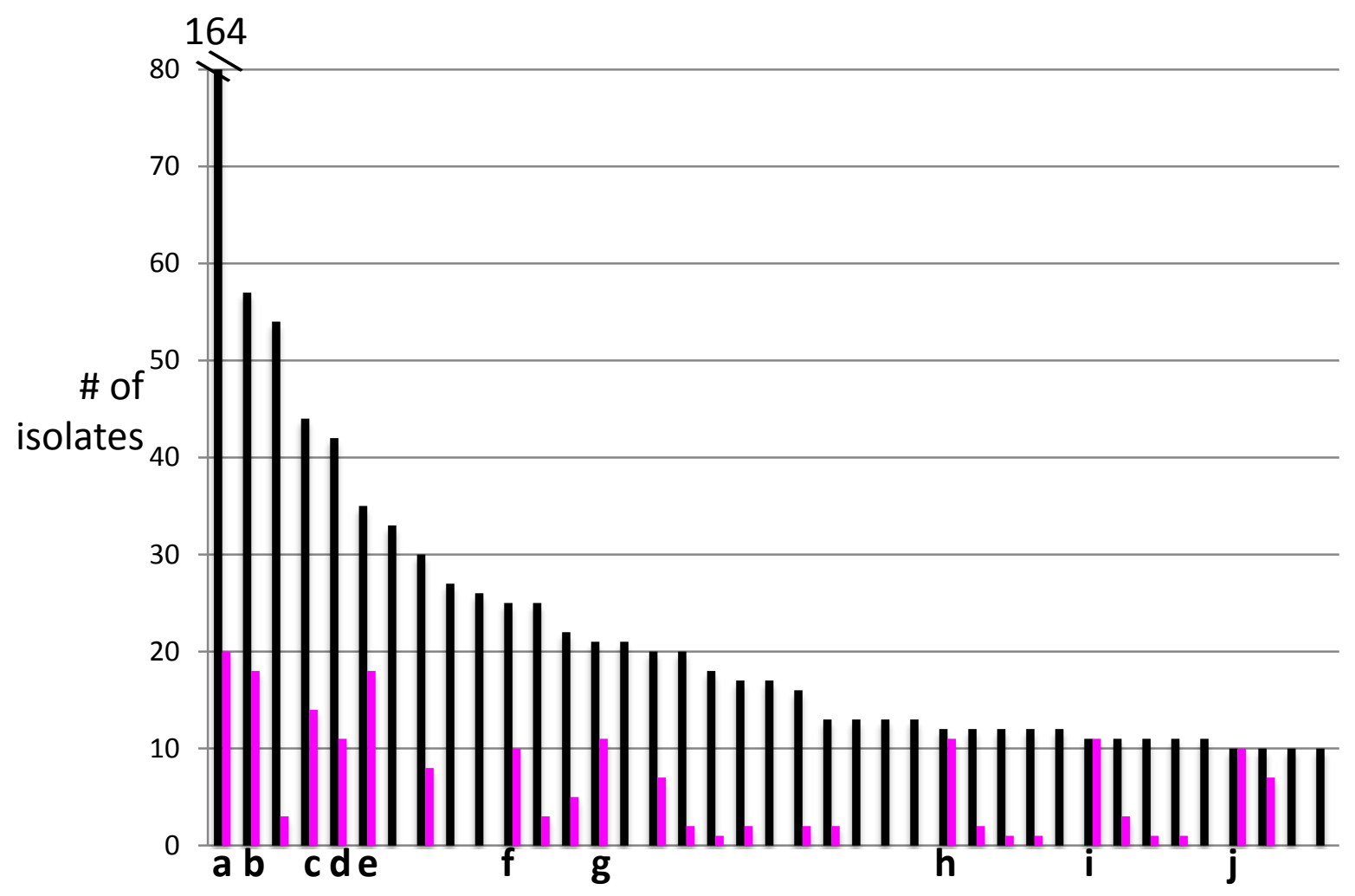

Figure 7. Distribution of numbers of typed isolates by collection site, originating either from any fish (black) or from fish reported to have IHN disease (pink), ordered on numbers of all isolates. Out of the 252 collection sites in this report, only the 39 sites with $\geq 10$ isolates are shown. The scale is set to best visualize the numbers of disease events, so the number of isolates from the first site, which is greater than 80 typed isolates is indicated above. The 10 sites with $\geq 10$ cases of reported disease events are lettered, and site specific details of IHNV subgroups and primary host species are indicated for each site in Table 4. 